\title{
Diphtheria
}

\section{What is diphtheria?}

Diphtheria is a contagious and potentially life-threatening bacterial infection that usually affects the nose and throat. Diphtheria was a common cause of death in children up until the 1940s but has now almost disappeared in Australia due to immunisation. It is re-emerging as a problem in some areas of the world with poor immunisation rates.

The bacteria that cause diphtheria are called Corynebacterium diphtheriae and Corynebacterium ulcerans. Some of these bacteria also produce a toxin.

\section{What are the symptoms?}

- Symptoms begin two to five days after exposure to the diphtheria bacteria. The first symptoms are usually a sore throat and a mild fever. A membrane forms over the throat and tonsils that can make it hard to swallow and breathe. The infection can also cause the lymph glands and tissues on both sides of the neck to swell.

- A toxin formed by some diphtheria bacteria can cause inflammation of heart muscle and nerves which can be fatal.

- Sometimes diphtheria can cause small skin sores that form larger ulcers, commonly on the legs.

- People usually take between two and five days to show symptoms after infection.

\section{How is it spread?}

- Diphtheria bacteria can live in the mouth, nose, throat or skin of infected individuals.

- People can get diphtheria by breathing in the diphtheria bacteria after an infected person has coughed or sneezed. People can also get diphtheria from close contact with discharges from an infected person's mouth, nose, throat or skin.

- People with diphtheria are infectious for up to four weeks from the onset of symptoms. Some people may become carriers of the bacteria and are infectious for longer.

- C. ulcerans is occasionally associated with consumption of unpasteurised milk or contact with animals.

\section{Who is at risk?}

Anyone who comes in contact with diphtheria during its infectious phase who has not had diphtheria in the past or has not been fully immunised is at risk.

\section{How is it prevented?}

- Diphtheria vaccination protects against the disease. It is part of the standard vaccination schedule and is given as DTP vaccine, which protects against diphtheria, tetanus and pertussis (whooping cough) in combination.

- DTP vaccine should be given at two, four and six months of age, followed by booster doses at four years and at 15 years of age.

- A high vaccination rate must be maintained to protect the population from resurgence of this disease.

\section{How is it diagnosed?}

- A doctor can diagnose diphtheria based on a clinical examination when the membrane is seen in the throat, and by testing throat swabs in a laboratory.

- Special laboratory tests are needed to detect the toxin.

\section{How is it treated?}

Diphtheria infection is treated with antibiotics. Sometimes an antitoxin is also needed.

\section{What is the public health response?}

Laboratories, school principals and directors of childcare centres and hospitals are required to notify cases of diphtheria to the local Public Health Unit under the Public Health Act, 1991. Public Health Units investigate cases and their contacts to review possible sources of infection and prevent further spread. Cases are isolated until they are not infectious. People who have had close or prolonged contact with a case may also be at risk of infection. Some contacts of cases are given antibiotics to stop the infection from developing.

\section{NSW}

